\title{
"Is die duiwel los?" Nuwe-Testamentiese perspektiewe op die stryd tussen Christus en die Bose
}

\author{
Stephan Joubert \\ Departement Nuwe Testament \\ Universiteit van Pretoria \\ PRETORIA \\ E-pos: stefan@ccnet.up.ac.za
}

\begin{abstract}
"Is the devil on the loose?" New Testament perspectives on the struggle between Christ and Satan

A brief summary of the views of Jesus, Paul and John regarding the struggle between Christ and Satan is first presented. This is followed by a discussion of the position of the followers of Jesus in this "eschatological" battle. Apart from modern theological epistemologies that interpret early Christian views regarding the struggle between Christ and Satan in terms of a primitive, mythical worldview, the metaphysical worldview of the New Testament is taken seriously in this article. It is argued that both God's metaphysical involvement in history, as well as the reality of evil, must be taken into consideration if modern believing communities still want to lay claim to legitimately being part of the apostolic tradition. This, however, does not call for any fixation on evil in its various manifestations, but for a constant awareness of Christ's eschatological victory over all opposing forces.
\end{abstract}

There are two equal and opposite errors into which our race can fall about devils. One is to disbelieve in their existence. The other is to believe, and to feel an excessive and unhealthy interest in them. They themselves are equally pleased with both errors" - C. S. Lewis, The Screwtape Letters (1961:15). 


\section{Die afwesigheid van die Bose}

"Die Nuwe Testament vertoon 'n mitologiese kosmologie. Vir die primitiewe mense van die Bybelse tyd funksioneer die Bose as verklaringsprinsipe vir vele onoplosbare probleme soos siekte en lyding." So sou die konsensus onder vele teoloë en ander geleerdes oor die bestaan van die Bose sedert die tyd van die Aufklärung opgesom kon word.

Binne Westerse denke word min ruimte gelaat vir die moontlikheid van metafisiese ingrype in die geskiedenis. Vir Nel (1987:13) vereis "die konflikterende getuiensis oor die Bose in die Ou Testament en die voorChristelike Judaïsme(s)" byvoorbeeld dat individue nie in die bestaan van Satan hoef te glo nie. Van Aarde (1987:34-35) veronderstel op sy beurt dat daar wel sprake is van boosheid in die wêreld; egter sonder dat dit 'n persoonlike gestalte aanneem. Boosheid is volgens hom soos die gate in 'n Switserse kaas. Dit is ondefinieerbaar; dit bestaan binne in die kaas as "nie-kaas." Die Amerikaanse Nuwe-Testamentikus, John Dominic Crossan (1994:85), wat eweneens die bestaan van demoniese wesens ontken, aanvaar "... that there is something real, as distinct from faked or simulated, behind events understood by participants as possession". Hy is egter van oordeel dat moderne psigiatriese interpretasies van sogenaamde demoniese verskynsels die korrekte sleutel tot die verstaan hiervan inhou.

\section{Probleemstelling: ' $n$ hernude belangstelling in die Bose}

As dit aan die een kant waar is dat die duiwel binne intellektuele Westerse kringe min of meer van die toneel verwyder is, is dit aan die ander kant waar dat daar tans in kerklike kringe 'n "nuwe belangstelling" in die Satan is. Hierdie belangstelling in die Bose is ' $n$ indirekte gevolg van die sogenaamde postmodernistiese tydsgees waarin ons tans verkeer wat onder andere as ' $n$ protes teen die outoritarisme en vaste sekerhede van die modernisme ontwikkel het (vgl. Connor, 1995:228). 'n Nuwe openheid vir die metafisiese, tesame met die soeke na nuwe antwoorde en verklarings vir die vele onopgeloste vrae waarmee individue gekonfronteer word, het ook binne baie godsdienstige kringe aanleiding gegee tot ' $n$ sogenaamde herontdekking van die realiteit van die Bose. Andersyds is hierdie belangstelling in die duiwel 'n teenreaksie teen die twintigste-eeuse stilswye oor hom binne intellektuele en kerklike kringe. In die woorde van Russell (1986:300):

Skeptics suggest that the idea of the Devil is socially destructive, that to believe in the Devil is to grant evil too much power. Certainly it is spiritually unhealthy to dwell upon the idea of the Devil in any way that lessens one's attention to grace. But in the late twentieth century the Devil seems to be receiving too little attention than too much. 


\section{Doelstelling}

Christelike epistemologieë word hoofsaaklik gebou op die Bybel en op kerklike tradisies. Aangesien albei hierdie fasette die Bose as realiteit aanvaar, behoort enige Christelike teologie wat aangebied word as 'n gelowige nadenke oor die "apostoliese tradisie" soos wat dit neerslag vind in die Nuwe Testament, rekening te hou met die kosmologiese wêreldbeeld wat ten grondslag aan hierdie dokumente lê. Uitgaande van die pas genoemde kenteoretiese vertrekpunt is dit die doel van hierdie bydrae om ' $n$ algemene oorsig oor Nuwe-Testamentiese sieninge van die stryd tussen Christus en die Bose aan te bied. Meer spesifiek: aan die hand van 'n "deskriptiewe benadering" tot die tersaaklike NuweTestamentiese tekste sal ' $n$ aantal belangrike teologiese riglyne in hierdie verband uitgelig word. Hierdie analise sal egter voorafgegaan word deur 'n kort bespreking van algemene Joodse opvattinge oor bose magte rondom die eerste eeu, aangesien die Joodse milieu die sosiokulturele raamwerk gevorm het waarbinne die prediking van Jesus sy historiese beslag gekry het. Ten slotte word enkele beginsels ook aan die orde gestel wat betrekking het op die rol en verantwoordelikhede van gelowiges in hierdie stryd tussen Christus en die Bose.

\section{Vasgevang in 'n greep van vrees: bose magte in die Joodse wêreld rondom die Nuwe-Testamentiese era}

Die alledaagse wêreld waarbinne die Jode hulleself rondom die eerste eeu bevind het, was gevul met die teenwoordigheid van bose magte. Hierdie wesens was woonagtig in plekke soos woestyne, in die lug, grond, en in water (vgl. ook Matt. 12:43; Ef. 2:2; Op. 13:1 e.v.). Hulle kon in verskillende gestaltes verskyn, soos in die vorm van wolwe, honde, paddas, onrein voëls en slange (vgl. ook Op. 9:3-7; 12:3; 16:13).

Volgens Joodse opvattinge het demoniese magte hul slagoffers deur liggaamsopeninge binnegedring. Vanweë die gevare verbonde aan demoniese "besoedeling" is kontak met heidene, onrein persone, en siekes ontmoedig (Böcher, 1972:14). Die eet van kos wat nie aan Joodse reinheidsvoorskrifte voldoen nie was verbode; so ook ongeoorloofde seksuele gedrag, aangesien dit aanleiding tot demoniese besetting kon gee.

Wanneer demone mense beset het, het dit gelei tot onnatuurlike gedrag aan die kant van laasgenoemdes, soos emosionele onstabiliteit, stuiptrekkings, gewelddadige optrede, en dies meer. Demoniese magte kon mense ook siek maak, en uiteindelik hulle dood veroorsaak. 
Demoniese magte is veral deur duiweluitdrywers of eksorsiste teengestaan. Hierdie persone het dikwels gebruik gemaak van "eksorsistiese formules" wat ingelei is met frases soos: "Ek beveel jou ..."; gevolg deur die vermelding van die name van allerlei goddelike magte en 'n bevel dat die demoniese magte hul slagoffers moet verlaat (Fergusson, 1984:9).

In die Joodse geskrif, Tobit, verneem ons van bepaalde rituele wat ingespan is om demone te verdryf. In Tobit 6 word naamlik vertel hoedat Tobias, die seun van Tobit, verlief raak op 'n vrou met die naam Sara. 'n Sterk demoon, genaamd Asmodeus, weier egter dat enige man naby aan haar kom. Die engel Rafael beveel dan vir Tobias om van die as van brandende wierook te vat en dit saam met die hart en lewer van 'n vis te brand, dan sal die demoon padgee.

Saam met die gebruik van godsdienstige formules en rituele, het eksorsiste ook homeopatiese middels gebruik om duiwels te besweer. Aan die hand van die sogenaamde similia similibus-beginsel is klein dosisse van dieselfde stowwe as dié waarin die duiwels hulle sou bevind, soos grond, water of plante, gebruik om hulle te verdryf. Amulette is soms ook aan persone gegee om te dra om hulle teen die Bose te beskerm. Eweneens is allerlei ornamente en simbole in woonhuise aangebring om bose magte af te skrik.

Wat die oorsprong van hierdie bose magte betref, verbind die apokaliptiese geskrif, 1 Henog, dit aan die optrede van bose engele wat onder aanvoering van Asasel met vroue op aarde seksuele gemeenskap gehad het. Die afgestorwe geeste van die reuse wat uit hierdie ongeoorloofde gemeenskap gebore is, is demoniese wesens wat mense nou oral tot boosheid verlei (1 Henog 69:4-6); gevalle sondaars aankla (1 Henog 40:7), en wat veroordeeldes in die onderwêreld pynig (1 Henog 98:4 e.v.). Aan die einde van die tyd sal die uitverkore figuur of Messias op sy troon oor Asasel en al hierdie bose magte oordeel (1 Henog 55:4).

\section{Die optrede van Jesus in die evangelies}

\subsection{Jesus se duiweluitdrywings}

Jesus se aardse optrede vind plaas binne die Joodse milieu van die eerste eeu wat gekenmerk is deur 'n voortdurende bewussyn van die vernietigende aktiwiteite van bose magte. Die stryd teen hierdie magte is egter nie die hoofdoel van Jesus se sending nie. Veel eerder staan sy optrede in die teken van die koms van die koninkryk van God (Mark. $1: 15)$. Jesus se verkondiging en wonders dien sodoende as sigbare 
manifestasies van God se nuwe eskatologiese heerskappy (Merklein, 1995:55).

Jesus se koms en optrede lei die eskatologiese oordeel en triomf oor Satan in en vergestalt terselfdertyd ook hierdie oorwinning. Die Bose word nou, met die aanbreek van die Messiaanse era, soos 'n weerligstraal uit die hemel gewerp (Luk. 10:18; Joh. 12:31 - vgl. ook Becker, 1996:132). Daar bestaan nooit enige twyfel oor die uitslag van die konflik tussen Jesus en die Bose nie. Wanneer Satan as "toetser" byvoorbeeld sy opwagting in die woestyn maak om Jesus van sy sending te laat afsien (Mark. 1:12-13 par.), tree laasgenoemde as oorwinnaar uit hierdie "strydgesprek." Satan se ware identiteit word terselfdertyd ontmasker. Hy is geen god nie, maar hoogstens net 'n eskatologiese teenspeler in die stryd teen Jesus.

Verskeie konfrontasies tussen Jesus en bose magte vind deur die loop van sy openbare bediening plaas (Matt. 4:23 e.v.; Mark. 1:32; Luk. 6:1718). Wanneer hierdie magte hul terrein oortree deur menslike liggame as hul woonplekke te beset (Mark. 1:25-26; 5:1-20; 9:14-29), volg dramatiese reaksies gewoonlik wanneer hulle met Jesus in aanraking kom. Omdat die demone Jesus se ware identiteit ken ("Jesus van Nasaret" (Mark. 1:24), "Seun van die Allerhoogste (Mark. 5:7), "die Heilige wat van God af kom" [Mark. 1:24]), gaan hulle dikwels hard aan die skree, gooi hulle slagoffers op die grond neer, smeek Jesus om genade (Mark. 1:23; $7: 25)$, ensovoorts. By geleentheid probeer demoniese magte selfs om aan die hand van "afweer-rites" hulleself teen Jesus te beskerm. In Markus 5:7 verneem ons byvoorbeeld hoedat 'n bose mag Jesus beveel om hom nie seer te maak nie. Ook die voorafgaande uitdrukking van hierdie demoniese mag: "wat is daar tussen my en jou?" funksioneer as 'n "verbale verdedigingsmeganisme" teen Jesus se mag (Twelftree, 1993:64).

In teenstelling met Joodse duiweluitdrywers met hul formules, amulette en rituele, maak Jesus slegs gebruik van "magswoorde" om demoniese magte te verdryf (Mark. 9:25; Matt. 8:16). Geen gebede, of die vermelding van hemelse name gaan met sy eksorsismes gepaard nie. Jesus se kragbelaaide woorde is telkens voldoende om sy oorwinning oor die domein van die Bose sigbaar te vergestalt.

\subsection{Jesus se woorde oor Satan}

In die bekende Beëlsebul-strydgesprek (Mark. 3:22-27; Matt. 12:22-30; Luk. 11:14-23) word Jesus, in reaksie op sy uitdrywing van 'n bose mag uit 'n stom man, daarvan beskuldig dat hy dit doen met die hulp van Beëlsebul, die aanvoerder van die bose magte. Die Joodse 
godsdienstige leiers veronderstel met ander woorde dat Jesus kop in een mus met sterk bose magte is wat Hom in staat stel om van swakker demone ontslae te raak. Hierteenoor benadruk Jesus dat die domein van die Bose ' $n$ eenheid is onder aanvoering van Satan. Sy stryd is sodoende nie teen individuele manifestasies van die Bose gerig nie, maar teen sy ganse ryk. In die woorde van Becker (1996:133-134):

Der Vollzug je einzelner Dämonenaustreibungen ist also nicht nur etwa Episodisches, sondern ein Aspekt desjenigen umfassenden Horizonts, der mit der Gottesherrrschaft selbst thematisiert ist, also endzeitliches zur Herrschaft Kommen Gottes.

Deur die vinger van God (Luk. 11:20), of deur die krag van die Gees van God (Matt. 12:28), stroop Jesus die Satan van sy gewaande mag. Teenoor sy Joodse teenstanders, wat waarskynlik van mening was dat die krag van God se Gees afwesig was onder die Jode (Keener, 1999:363), maak Jesus se uitdrywing van demoniese magte dit duidelik dat God se koninkryk, sy nuwe wêreld, reeds aangebreek het. Meer spesifiek: aan die hand van 'n oorlogsbeeld (vgl. Mark. 3:27; Matt. 12:29; Luk. 11:21-22) interpreteer Jesus sy stryd met Satan as 'n inname van laasgenoemde se versterkte vesting. Die Een wat sterker is as "die sterk man," neem nou sy vesting oor en vat sy "besittings" (diegene in die greep van die Bose) vir Homself. God se eskatologiese heil realiseer dus sigbaar in Jesus se bevryding van menslike slagoffers uit die greep van vyandige magte.

\section{Paulus: die kruis as triomf oor die teenmagte}

Binne die Pauliniese literatuur is daar sprake van allerlei "kragte, magte en heerskappye" (vgl. Rom. 8:38-39; 1 Kor. 15:24; Kol. 1:16; Ef. 1:20-21; $6: 12)$. Sonder om in die debat oor die identiteit van hierdie wesens verstrengel te raak (vgl. die omvattende besprekings in hierdie verband in Wink, 1984; Page, 1995), kan ons saam met Dunn (1998:106) aanvaar dat wanneer hierdie magte wel by Paulus na bonatuurlike wesens verwys, hulle deurgaans funksioneer as teenmagte wat God se heilsplanne met sy skepping probeer dwarsboom. Meer konkreet: hierdie naamlose teenmagte is in staat om die kontak tussen mense en God te versper.

Supra-individualistiese kragte word in Paulus se geskrifte dikwels in verband gebring met die Bose as 'n individuele entiteit, sodat ons dan te make het met wat Dunn (1998:109) noem: "an existentially real power cohered in a single focus - experienced as malevolent and therefore conceived of as personal". Paulus ken Satan onder andere as "die god van hierdie sondige tydsgewrig" (2 Kor. 4:4) wat in staat is om on- 
gelowiges te verblind sodat hulle nie die lig van die evangelie sien nie. Satan is ook "die heerser oor die koninkryk van die lug" (Ef. 2:2); dit wil sê, die ruimte tussen hemel en aarde wat dikwels in die antieke tyd as die domein van bose magte beskou is (Luz, 1998:131).

Vir Paulus staan die oorwinning van Christus oor al hierdie magte bo alle twyfel vas. Christus bevry die ganse kosmos uit die greep van demoniese duisternis (vgl. Barnett, 1997:220). Veral in sy briewe aan die Efesiërs en die Kolossense, waar die kosmologiese implikasies van Christus se sterwe en opstanding duidelik uitgespel word, word sy algehele heerskappy oor al die magte benadruk (bv. Ef. 1:20-22; Kol. 2:10). Hierdie triomf is reeds aan die kruis behaal. Daar is alle teenmagte eens en vir altyd in Christus se magtige triomftog verslaan. Hulle is kaal gestroop; hul heerskappy oor die wêreld het tot 'n abrupte einde gekom (Kol. 2:15). Na Christus se oorwinning aan die kruis het $\mathrm{Hy}$ volgens Efesiërs 4:10 die belangrikste posisie in die hemel ingeneem. Hy het selfs "krygsgevangenes" daarheen saamgeneem en geskenke aan sy volgelinge uitgedeel (aldus Ef. 4:8, as 'n Christologiese interpretasie van Ps. 68:19.) Tipies van antieke "oorwinningsmetaforiek" moes enige oorwinnaar krygsgevangenes aan sy volgelinge vertoon as bewys van sy triomf en ook oorlogsbuit uitdeel, soos wat Christus volgens Paulus inderdaad ook na sy hemelvaart doen! As Skepper en Skeppingsmiddelaar (Kol. 1:15-20), is Christus nou die Een wat beheer oor alles in die skepping uitoefen. Hy is daarom ook in staat om 'n einde te bring aan die vernietigingswerk van die magte in sy volgelinge se lewe (Gnilka, 1994:330).

Die kruisgebeure het volgens Paulus ingrypende implikasies vir alle teenmagte wat gelowiges se bestaan bedreig. Die dood as finale vyand (1 Kor. 15) is deur Christus se opstanding van sy krag en verskrikking gestroop. So ook die vlees, oftewel die menslike geneigdheid tot sonde. Aangesien gelowiges nou saam met Christus gekruisig is en sodoende dood is vir die sonde (Rom. 6), het laasgenoemde as 'n vyandige mag nie meer die finale sê oor hulle lewens nie. Gelowiges staan nou onder die beheer van die Gees wat hulle permanent as God se eiendom beseël (2 Kor. 1:21-22; Ef. 1:13-14). Daarom kan niks hulle nou van God se liefde skei nie - selfs nie eens teenmagte of die dood nie (Rom. 8:31-39). Op grond van hierdie nuut toegerekende status as eskatologiese gawe aan die ganse kerk van Christus, roep Paulus gelowiges dikwels op tot "korrekte" etiese gedrag (bv. Gal. 5; Rom. 6). In die lig van die herskeppende teenwoordigheid van die Gees by gelowiges, is hulle, aldus Paulus, immers nou in staat om aan die Here se eise te voldoen en om ook weerstand teen sonde te bied (vgl. Witherington, 1998:278-286). 


\section{Openbaring: Satan onder huisarres!}

\subsection{Die Sataniese magte is los!}

In 'n dramatiese narratief, wat ingebed is binne die simboliese wêreld en taal van die $\mathrm{Ou}$ Testament en die Joodse apokaliptiek (vgl. die uitgebreide besprekings in hierdie verband in Du Rand, 1991; Hahn, 1998), neem die skrywer/sienier (oftewel, Johannes, soos wat hy homself in Op. 1 identifiseer) die lesers op 'n visioenêre reis. Openbaring 4-20 speel af binne die raamwerk van Christus se hemelvaart en die wederkoms. Die tyd op aarde tussen hierdie twee gebeurtenisse word simbolies aangedui as twee en veertig maande; drie en 'n half jaar, of drie en 'n half dae (Op. 11-13). In sy visioene beskryf die siener die lyding wat die kerk gedurende hierdie tyd onder die aanhitsing van Sataniese magte moet verduur, sowel as God se straf wat gedurende hierdie ganse tydperk oor sondaars voltrek word - vgl. byvoorbeeld die sewe seëls (Op. 6-8), die 7 trompette (Op. 8-9/11), die 7 oordeelsbakke (Op. 15-16). Hierdie lydingstyd van twee en veertig maande wat tot en met die terugkeer van die Here duur, is 'n tyd waartydens die draak (oftewel Satan - Op. 12) heerskappy oor die goddelose wêreld uitoefen deur bemiddeling van twee diere (Op. 13), en deur die bose vrou, Babilon (Op. 17). Laasgenoemde Sataniese magte se taak behels volgens Johannes die verleiding van die wêreld tot aanbidding van die draak, en die vernietiging van die kerk.

\subsection{Drie perspektiewe op Christus se heerskappy}

\subsubsection{Openbaring 5}

Die hemelse toneel in Openbaring 4-5 vorm die sleutel tot die verstaan van Openbaring (Vögtle, 1981:54). Uit hierdie hoofstukke blyk dit dat die hemelse troonsaal, oftewel, die beheersentrum van die kosmos, volledig onder die beheer van God, die Gees en Christus staan. Veral in hoofstuk 5 , waar Christus na sy hemelvaart op die toneel verskyn, word benadruk hoedat $\mathrm{Hy}$, as die geslagte Lam, terselfdertyd ook Heerser oor die sondige wêreld is. Christus is daarom in staat om God se raadsplan uit te voer deurdat Hy die verseëlde boek uit God se hand neem en die sewe seëls oopmaak (Op. 6-8; vgl. ook Aune, 1997: CDROM).

\subsubsection{Openbaring 12}

In Openbaring 12 tref ons 'n tweede perspektief op Christus se "hemelse troonsbestyging" aan. In hierdie toneel verneem ons naamlik van die konflik tussen die draak en die vrou wat 'n Kind ("Christus") in die wêreld bring. $\mathrm{Na}$ die Kind se hemelvaart maak die draak sy opwagting in die hemel as ongenooide gas by eersgenoemde se troonsbestyging (Aune, 
1998a: CDROM). Johannes beskryf voorts in sy visioen hoedat 'n skermutseling tussen Satan en die Here se engele onder aanvoering van Migael, plaasvind. Na sy neerlaag teen die hemelse weermag word die draak en sy bose magte uit die beheersentrum van die kosmos gegooi. Hierna word Satan se magsgebied ruimtelik tot die aarde beperk. Terselfdertyd word daar ook 'n temporele perk aan sy "bewind" oor die sondige mensdom gestel. Slegs vir 'n beperkte tyd ("twee en veertig maande") word hy en sy Sataniese helpers naamlik toegelaat om met hul vernietigingswerk voort te gaan.

\subsubsection{Openbaring 20}

Openbaring 20, met sy vermelding van die duisendjarige ryk van Christus, bied 'n derde perspektief op Christus se troonsbestyging en heerskappy. Hierdie vrederyk breek met Christus se hemelvaart aan wanneer Hy beheer oorneem van die hemelse skares, asook van die verdere verloop van die geskiedenis. Almal wat gedurende die twee en veertig maande van swaarkry op aarde ("die tyd tussen hemelvaart en wederkoms") beswyk sonder om voor die dier die knie te buig, sluit volgens 20:7 triomfantlik by Christus in sy hemelse vrederyk aan (Aune, 1998b: CDROM). Daar heers hulle saam met Hom tot aan die einde van die duisendjarige ryk, oftewel, totdat die wederkoms aanbreek.

Ten tye van die duisendjarige ryk in die hemel, wat temporeel korrespondeer met die twee en veertig maande van swaarkry op aarde, is Satan volgens 20:1-3 in die onderwêreld gebind. Hierdie beeld dui op die inperking van die Bose se naakte mag op aarde. Hy kan gedurende hierdie tydperk van "huisarres" slegs deur bemiddelling van die twee diere (Op. 13), en later ook deur me. Babilon (Op. 17), heerskappy oor sy domein uitoefen. Satan self verdwyn egter na sy uitbanning uit die hemel en sy kortstondige geveg teen die kerk (Op. 12) van die toneel af. Behalwe vir 'n kortstondige verskyning in Openbaring 16, is daar geen spoor van hom tot en met hoofstuk 20 te sien nie.

Wanneer Satan volgens die siener kort voor die wederkoms losgelaat word, is sy Sataniese helpers reeds deur Christus verslaan (Op. 19). Eweneens is die bose vrou Babilon ook vernietig (Op. 18). In 'n laaste desperate poging versamel Satan al sy oorblywende ondersteuners ("Die Gog en Magog") om teen die heiliges van die Here oorlog te maak. Hulle word egter verslaan en in die vuurpoel gegooi (Op. 20:7-10). Daarna eindig Openbaring in triomf as gelowiges in die nuwe Jerusalem by God hul woning maak. 


\section{Die kerk: deelnemers aan die stryd tussen Christus en die Bose}

Die Nuwe Testament teken Satan as 'n oorwonne vyand. Die kruisgebeure is die groot draaipunt in hierdie stryd. Deur Christus se sterwe en opstanding is Satan van sy gewaande mag oor die dood, die geskiedenis, en mense se lewe gestroop (Kol. 2:12-13; Heb. 2:14-15; Op. 1:17-18). God stuur nou die wêreldgeskiedenis af op die groot dag wanneer $\mathrm{Hy}$ in heerlikheid terugkom ten einde sy kerk en die ganse skepping finaal van verganklikheid en lyding te bevry (Rom. 8:17-25; Op. 20:11-15).

Die kerk deel volgens die Nuwe-Testamentiese getuienis volledig in die vrugte van Christus se oorwinning oor die Bose. Gelowiges is sodoende nie woonplekke van Sataniese magte nie (2 Kor. 6:14-7:1), maar gesamentlik die tempel van die Gees (1 Kor. 3:16; 6:19). Christene se nuwe identiteit word deurslaggewend bepaal deur die sterwe en opstanding van Christus, asook deur die nuutmakende werk van die Heilige Gees.

Gelowiges ken volgens die Nuwe Testament egter ook nog stryd, want selfs as ' $n$ verslaande opponent is die Bose steeds gedug. Hy is ' $n$ brullende leeu (1 Pet. 5:8); 'n meester van vermomming wat hom in 'n engel van die lig kan verander deur sy verdraaiings van die Goeie Nuus (2 Kor. 11:14). Hy lyk so onskuldig soos 'n lammetjie, maar sy stem klink egter soos dié van 'n draak (Op. 13:11).

Efesiërs 6:10-19 is een van die sleuteltekste in die Nuwe Testament waar gelowiges opgeroep word tot stryd teen die Bose. Opvallend egter van Paulus se inkleding van hierdie stryd (aan die hand van die beeld van 'n wapenrusting), is dat die verskillende aspekte van die gelowige se gevegsdrag uitsluitlik op God se nuwe werklikheid gerig word - nooit op Satan as direkte objek van die stryd nie. Gelowiges moet met ander woorde die stryd van die geloof stry deur die geregtigheid wat God gee as borswapen aan te hê; deur die Goeie Boodskap met ander te deel as skoene aan hulle voete; ensovoorts. Geen pre-okkupasie met Satan en sy magte word hier veronderstel of aangemoedig nie. Die "korrekte" stryd van die kant van die gelowige teen boosheid in watter gestalte ook al, vereis eerder 'n algehele lewensgerigtheid op God.

\section{Slotopmerkings}

Die Bose is geen handige verklaringsprinsipe vir lyding, of vir al die onoplosbare eksistensiële vraagstukke waarmee Nuwe-Testamentiese gelowiges worstel nie. Die Nuwe Testament ken boosheid immers in 
verskillende persoonlike gestaltes. Tog word gelowiges se aandag nooit op hierdie teenmagte gefikseer nie. Die Sataniese magte is immers gestroop van die gewaande mag wat die Joodse wêreld aan hulle toegedig het. Die Nuwe Testament vertoon daarom geen beheptheid met praktyke soos duiweluitdrywings nie. Wanneer sodanige praktyke wel binne die Nuwe-Testamentiese kerk plaasvind (bv. Hand. 16), word dit altyd op "buitestaanders" uitgevoer; dit wil sê, op mense wat nie deel van die kerk is nie. Geen rituele, amulette of towerspreuke word ooit deur die eerste gelowiges gebruik ter beskerming teen die Bose nie. Die opgestane Christus se krag, soos vergestalt in die teenwoordigheid van die Heilige Gees, is ten alle tye die wapenrusting van gelowiges.

Boosheid word volgens die Nuwe Testament somtyds ook vergestalt in verskillende supra-persoonlike gestaltes. Bepaalde sosiale en politieke stelsels kan op gegewe momente binne die geskiedenis hulleself as goddeloos, as flagrante skendings van Bybelse waardes, aandien. In hierdie verband sou die laat eerste-eeuse Romeinse keiserryk, wat in die boek Openbaring vergestalt word in die dier uit die aarde (Op. 13) en die bose vrou Babilon (Op. 17), as voorbeeld uitgelig kon word. Sonde setel volgens Paulus egter ook as 'n aktiewe teenmag in vele indiwidue se lewe (Rom. 7; Gal. 5). Die werking van hierdie, en ander teenmagte soos die vlees en die wet (vgl. Gal. 3-4), staan by die apostel lynreg teenoor die nuutmakende krag van Christus en die Gees.

In die lig van die voorafgaande bespreking blyk dit dat 'n metafisiese wêreldbeeld noodsaaklik is vir enige Christelike tradisie wat met die Bybel as God se openbaringswoord rekening hou. Binne sodanige wêreldbeeld moet ruimte gelaat word vir God se handelinge binne die geskiedenis. Dit vereis ook 'n bewussyn van die werking van boosheid in verskillende persoonlike en onpersoonlike gestaltes.

\section{Bibliografie}

AUNE, D. 1997. Revelation 1-5. Waco : Word. (Logos Library System CDROM: Nelson Publishers.)

AUNE, D. 1998a. Revelation 6-16. Waco : Word. (Logos Lybrary System CDROM: Nelson Publishers.)

AUNE, D. 1998b. Revelation 17-22. Waco : Word. (Logos Lybrary System CDROM: Nelson Publishers.)

BARNETT, P. 1997. The Second Epistle to the Corinthians. Grand Rapids : Eerdmans.

BECKER, J. 1996. Jesus von Nazaret. Berlin : De Gruyter.

BÖCHER, O. 1972. Das Neue Testament und die dämonischen Mächte. Stuttgart : Katholisches Bibelwerk.

CONNOR, S. 1995. Postmodernist culture. An introduction to theories of the contemporary. Oxford : Blackwell.

CROSSAN, J.D. 1994. Jesus. A revolutionary biography. San Francisco : Harper. 
DUNN, J.D.G. 1998. The theology of Paul the apostle. Grand Rapids : Eerdmans.

DU RAND, J.A. 1991. Johannine perspectives. Introduction to the Johannine Writings - Part 1. Halfweghuis : Orion.

FERGUSSON, E. 1984. Demonology of the early Christian world. Lewiston : Mellen.

GNILKA, J. 1994. Theologie des Neuen Testaments. Herder : Freiburg.

HAHN, F. 1998. Frühjüdische und urchristliche Apokalyptik. Neukirchen-Vluyn : Neukirchener Verlag.

KEENER, C.S. 1999. A commentary on the Gospel of Matthew. Grand Rapids : Eerdmans.

LEWIS, C.S. 1961. The Screwtape Letters. New York : MacMillan.

LUZ, U. 1998. Der Brief an die Epheser. (In Becker, J. \& Luz, U. Die Briefe an die Galater, Epheser und Kolosser. Göttingen : Vandenhoeck. p. 107-182.)

MERKLEIN, H. 1995. Die Jesusgeschichte - synoptisch gelesen. Stuttgart : Katholisches Verlag.

NEL, P.J. 1987. The conception of evil and satan in Jewish traditions in the preChristian period. (In De Villiers, P.G.R., ed. Like a roaring lion. Essays on the Bible, the church and demonic powers. Pretoria : University of South Africa. C.B. Powell Bible Centre. p. 1-21.)

PAGE, S.T. 1995. Powers of evil. A Biblical study of Satan and demons. Grand Rapids : Baker.

RUSSELL, J.B. 1986. Mephistopheles. The Devil in the modern world. Ithaca : Cornell.

TWELFTREE, G.H. 1993. Jesus the exorcist. A contribution to the study of the historical Jesus. Tübingen : Mohr.

VAN AARDE, A.G. 1987. Demonology in New Testament times. (In De Villiers, P.G.R., ed. Like a roaring lion. Essays on the Bible, the church and demonic powers. Pretoria : University of South Africa. C.B. Powell Bible Centre. p. 2237.)

VÖGTLE, A. 1981. Das Buch mit den sieben Siegeln. Die Offenbarung des Johannes in Auswahl gedeutet. Freiburg : Herder.

WINK, W. 1984. The Powers I: Naming the Powers: The language of power in the New Testament. Philadelphia : Fortress.

WITHERINGTON III, B. 1998. The Paul quest. The renewed search for the Jew of Tarsus. Leicester : Intervarsity.

\section{Kernbegrippe:}

bose magte in die antieke Joodse wêreld

Christelike wêreldbeeld

duiweluitdrywings in Jesus se bediening

geloofstryd as 'n volledige gerigtheid op God

kruis as simbool van oorwinning oor die magte

\section{Key concepts:}

Christian worldview

cross as symbol of victory over the powers

evil forces in the ancient Jewish world

exorcisms in the ministry of Jesus

struggle of faith as total orientation towards God 